\title{
The translucency of human teeth and its relation to esthetic restorative materials
}

\author{
Thuraya Abdulrahim Basudan ${ }^{1 *}$, Saif Juraythi Alqahtani ${ }^{2}$, Omar Abdulaziz Alsalmh², \\ Ekhlas Ishaq Kensara ${ }^{3}$, Mohammed Fareed Al Mughafi², Naif Abdullah Alamri², \\ Mohammed Bishi Hakami ${ }^{4}$, Wiaam Ibrahim Moussa ${ }^{5}$, Mohammed Abdulaziz Alshehri ${ }^{2}$, \\ Mohammed Ali Fayi ${ }^{2}$, Abdullah Mohmmed Mayyan ${ }^{6}$
}

\author{
${ }^{1}$ Department of Restorative Dentistry, East Jeddah Hospital, Jeddah, Saudi Arabia \\ ${ }^{2}$ College of Dentistry, King Khalid University, Abha, Saudi Arabia \\ ${ }^{3}$ College of Dentistry, King Abdulaziz University, Jeddah, Saudi Arabia \\ ${ }^{4}$ College of Dentistry, Jazan University, Jazan, Saudi Arabia \\ ${ }^{5}$ Dental Department, King Fahad Armed Forces Hospital, Jeddah, Saudi Arabia \\ ${ }^{6}$ College of Dentistry, Vision Colleges, Riyadh, Saudi Arabia
}

Received: 12 October 2021

Accepted: 27 October 2021

\section{*Correspondence:}

Dr. Thuraya Abdulrahim Basudan,

E-mail: tbasudan@moh.gov.sa

Copyright: (c) the author(s), publisher and licensee Medip Academy. This is an open-access article distributed under the terms of the Creative Commons Attribution Non-Commercial License, which permits unrestricted non-commercial use, distribution, and reproduction in any medium, provided the original work is properly cited.

\begin{abstract}
The main factor that can determine the harmonization and depth of color restorations for the adjacent other restorations or other teeth is the translucency of these restorations. Many factors can affect the translucency and color of the restoration material, including translucency parameter, lighting conditions, opacity, gloss, light scattering, and overall perception by the naked eye. Previous investigations have indicated that translucency is the main factor that can significantly contribute to the esthetic characteristics of the different dental restoration materials. In the present literature review, we have discussed the translucency of human teeth and its relation to esthetic restorative materials. Comparing the translucency of the different restoration materials with the naturally occurring human enamel is essential for adequate validation of their clinical application. It has been demonstrated that for $1 \mathrm{~mm}$ thick human enamel, a mean value for the translucency parameter of 15-19 should be considered. We have also highlighted the differences between the different types of resin composites and different shade groups, and findings indicate the superiority of some types and shade groups over others, as previously discussed. However, it should be noted that further research is still needed to unify the variously estimated values for the translucency parameter among the different restoration materials. This can help clinicians adequately interpret these data and obtain satisfactory clinical and patient-related outcomes.
\end{abstract}

Keywords: Translucency, Dental composite, Restoration, Resin composite, Glass ionomer

\section{INTRODUCTION}

Evidence indicates that successful restoration or dental prosthetic approaches should adequately fulfill the masticatory, esthetic, and phonetic issues. ${ }^{1}$ The main factor that can determine the harmonization and depth of color restorations for the adjacent other restorations or other teeth is the translucency of the recent restorations..$^{2-4}$ Accordingly, it has been demonstrated that many factors should be considered when choosing a suitable esthetic restorative material, including the strength, translucency, and color of the used material..$^{5}$ In this context, previous studies have focused their outcomes on the translucency and colors of the different restoration materials to validate 
their effectiveness and clinical applications regarding their esthetic compatibility. Many factors can affect the translucency and color of the restoration material, including translucency parameter, lighting conditions, opacity, gloss, light scattering, and overall perception by the naked eye. ${ }^{1}$ Previous investigations have indicated that translucency is the main factor that can significantly contribute to the esthetic characteristics of the different dental restoration materials. ${ }^{6-8}$ It has been used to describe the efficacy of different materials and has been reported to significantly impact the color bending effect, masking ability, and light-curing degrees intended for the different restoration materials. ${ }^{9}$

Contrast ratio $(\mathrm{CR})$ and translucency parameter are two different variables that have been commonly used in the literature to assess translucency of the different restoration materials. ${ }^{9,10}$ Many studies have evaluated the translucency of the different restorative materials. In the present literature review, we aim to provide evidence regarding the translucency of human teeth and its relation to esthetic restorative materials.

\section{METHODS}

This literature review was based on an extensive literature search in Medline, Cochrane, and EMBASE databases which was performed on $3^{\text {rd }}$ September 2021 using the medical subject headings (MeSH) or a combination of all possible related terms. This was followed by the manual search for papers in Google Scholar while the reference lists of the initially included papers. Papers discussing the topic were screened for relevant information, with no limitation placed on date, language, age of participants, or publication type.

\section{DISCUSSION}

To adequately evaluate novel restorative materials, the translucency of the human teeth should be used as a reference to these materials for an adequate clinical evaluation before they have been validated for application in clinical settings. Studies in the literature have indicated many factors to assess the translucency of the human teeth, upon which the clinical evaluation of these materials can be adequately established. ${ }^{11}$ Some of these factors include if the translucency parameters are similar to the human enamels with no significant impaction of the esthetic values and if these differences between the different restoration materials can be noticed with the naked eye, indicating the significant differences of these materials.

Furthermore, studies have analyzed the translucency differences based on the different anatomical locations of the maxillary human central incisors regarding the translucency of intact teeth. It has been demonstrated that a rate of 0.13 to $0.65 \%$ has been estimated for transmission and has been reported to significantly reduce between the incisal and cervical regions. ${ }^{12} \mathrm{~A}$ spectroradiometer has been reported to be the measurement tool of translucency of the central incisors of the human maxilla. ${ }^{13,14}$ The translucency parameter was also defined as the presence of color differences behind the intraoral tooth on black and white cloths. Accordingly, evidence indicates that the estimated translucency was significantly reduced from the incisal to the cervical regions as the estimated translucency parameter was found to be 15 at the incisal area, which was also observed to decrease to only five at the cervical area. However, it should be noted that evaluation of translucency in an esthetic restorative basis requires the application of layering techniques, and these aforementioned findings were based on an assessment of values related to the whole teeth.

Regarding the assessment of single dentin and enamels, evidence shows that increasing the wavelength of the incidence of light was significantly associated with an increase in the human enamel-related light transmission characteristics. ${ }^{15,16}$ Besides, it has been demonstrated that the translucency parameter and the CR were also used for the assessment of the translucency of both bovine and human dentin and enamels. ${ }^{17}$ The authors of this investigation also reported that two different aperture sizes for their spectrophotometers, including $\mathrm{TP}_{3}(3 \mathrm{~mm}$ round), and $\mathrm{TP}_{38}(3 \times 8 \mathrm{~mm}$ rectangular $)$ apertures. The authors reported that the estimated mean values of $\mathrm{TP}_{3}$ for the included $1 \mathrm{~mm}$ thick bovine dentin, bovine enamel, human dentin, and human enamel were found to be 15.2, 14.7, 16.4, and 18.7, respectively. The results of this investigation also showed that the estimated correlation coefficient was $0.87-0.91$ as they noticed a significant correlation between the increase in the visible-range wavelength and the translucency of the included dentin and enamels in this study. ${ }^{17}$ When interpreting this translucency of human teeth, researchers and clinicians should also care for the optical anisotropy of the assessed teeth.

Translucency consistency has been previously reported and indicates the consistent translucency parameters of the different shapes of objects under different lighting conditions to a certain extent. On the other hand, it has been demonstrated that changing the direction of lighting was associated with a significant impact on the translucency consistency of the human teeth as in some cases, failure was noticed. ${ }^{18,19}$

A previous investigation compared the parallel and perpendicular directions of the transmitted light intensities concerning the proximal surface of the tooth to investigate the light fluxes-related directional dependence. ${ }^{20}$ The authors have estimated mean values of 2.88, and 0.86 for the parallel and perpendicular transmitted intensities of light for dentin and enamel, respectively. It has been furtherly demonstrated by other investigations that to adequately evaluate translucency, a translucency parameter value of 15-19 might be 
considered the reference range for evaluating $1 \mathrm{~mm}$ thick human enamels. ${ }^{13,17}$

It should also be noted that translucency of the human teeth is hugely variable based on the used restorative esthetic material. In the current section, we will discuss some of the aspects of these variations regarding the commonest materials based on evidence from the included studies. Regarding the translucency of resin composites, different investigations have evaluated their effectiveness based on the shade, type, and brand of the restorative resin composite. Evidence indicates that translucency is significantly different between the different types of resin composites, including flowable and universal, and indirect and direct resin composites. A previous investigation compared the translucency of a direct resin composite material (Estelite Sigma, ES, Tokuyama, Tokyo, Japan) with an indirect one (BelleGlass NG, BG, Kerr, Orange, CA, USA), and the results were validated according to $1 \mathrm{~mm}$ thick models. ${ }^{21}$

In this context, the authors reported that after curing, the estimated mean values for the translucency parameter ranged between 21.5 and 10 to the BG-enamel shade and the BG-opaceous dentin shade. Therefore, it has been concluded that the indirect resin materials were associated with a wider range for the mean values of translucency parameter as compared to the direct materials in this study. It has also been concluded that the differences were perceivable when the authors found that the mean value for the translucency parameter to be $>2$ for the shade and material group combinations. Another investigation also compared the universal and flowable dental resin composites that are composed of the same brand materials using a $2 \mathrm{~mm}$ thick model. ${ }^{22}$

The authors reported that the mean translucency parameters were higher with the flowable resin composites which attributed to a significant color difference between the different materials that were used in this investigation. Other investigations have also evaluated the translucency parameter of the flowable bulk-filling resin composites. ${ }^{23-27}$ The authors of these investigations reported that the thickness of the specimen significantly impacted the mean translucency parameters.

For instance, it has been demonstrated that translucency was noticed for 2-3 mm thick specimens of the universal/flowable composite and 5-6 $\mathrm{mm}$ thick specimens of the bulk-filling composites. Accordingly, it has been concluded that conventional composites were associated with a more masking ability than the bulkfilling ones. Framework materials of the dental resin composites can also influence translucency. In this context, it has been demonstrated that the color of the prosthesis was significantly impacted by the thickness of the used material, although it has been reported that it might have similar efficacies compared to the conventional ones, however, this efficacy has been reported to be within a certain range.
Previous investigations have also assessed the translucency of glass ionomer-based materials. ${ }^{28-31} \mathrm{~A}$ previous investigation compared the opacity of resin composites with glass ionomer-based materials. ${ }^{32}$ It should be noted that different glass ionomer-based materials were introduced to the clinical settings with more enhanced translucency effects than the initially reported materials. ${ }^{33}$ However, evidence indicates that despite these marvelous updates, a significant reduction in the opacity of these materials is still needed to be comparable with the resin composites. ${ }^{34}$

Whether the modality was cured using acid-based reactions or with light-curing has been reported to significantly impact the translucency of resin-modified glass-ionomers. There has been a significant difference between the non-radiation exposed materials and others that were light-cured in terms of translucency. Furthermore, it has been reported that the powder shade and content of 2-hydroxyethyl methacrylate can significantly impact the translucency parameter. ${ }^{35,36}$ The differences in translucency by brand and shade of the used materials were also reported among many investigations in the literature. A previous investigation compared the values of light transmittance and the translucency parameters among 7 different resin brands among 3 different shade groups, including translucent, dentin, and enamel. ${ }^{37}$ It has been demonstrated that the translucency parameter significantly differed between the different brands among the included shade groups. A moderate correlation was also estimated for each shade group with translucency, and with most of the investigated brands.

Another investigation also compared the translucency parameter of the opaque, enamel, and body shade groups of the resin composites at various thickness specimens, including $0.5,1,2,3$, and $4 \mathrm{~mm}$, in addition to using white and black backgrounds. ${ }^{38}$ The authors reported that the translucency of the used shade groups significantly increased when the thickness of the specimen was reduced, irrespective of the shade group. Besides, the opaque shade group was associated with the least estimated value of translucency parameters as compared to other included shades. Finally, the estimated mean translucency parameter was lower in the used $1 \mathrm{~mm}$ thick enamels than the human ones, which might be attributed to an installation error in the used backgrounds in this study.

The association between masking efficiency and the value of the translucency parameter was also reported. It has been demonstrated accordingly that the usual shade composites were more translucent than the opaque ones. ${ }^{39-41}$ Thus, evidence indicates that significant masking of the dark background can be successfully achieved by using opaque shade composites.

In another investigation by Ikeda et al the authors used 2 $\mathrm{mm}$ thick specimens to compare the translucency of 
conventional and opaque shade resin composites. ${ }^{42}$ It has been demonstrated that the estimated mean value of the transparency parameter for the opaque shade composites was smaller than the conventional one. It has been furtherly demonstrated that a thickness of 0.5-4 $\mathrm{mm}$ with an estimated interval of $0.5 \mathrm{~mm}$ was adequate to mask the colored tooth structure and black oral cavity by the opaque shade resin composites.

Another in vitro investigation also aimed to estimate the translucency parameter for 6 opaque dental resin composites using 4 different backgrounds to adequately evaluate the mean value for these parameters in an approach similar to the oral cavity. It has been indicated that increasing the thickness of the specimens was significantly associated with increased translucency parameters. ${ }^{40}$ Previous review studies have also evaluated reference ranges for the translucency parameters to be effectively and easily compared to others for easy interpretation of the findings among the different studies. $^{3,43}$

\section{CONCLUSION}

Comparing the translucency of the different restoration materials with the naturally occurring human enamel is essential for adequate validation of their clinical application. It has been demonstrated that for $1 \mathrm{~mm}$ thick human enamel, a mean value for the translucency parameter of 15-19 should be considered. We have also highlighted the differences between the different types of resin composites and different shade groups, and findings indicate the superiority of some types and shade groups over others, as previously discussed. However, it should be noted that further research is still needed to unify the variously estimated values for the translucency parameter among the different restoration materials. This can help clinicians adequately interpret these data and obtain satisfactory clinical and patient-related outcomes.

Funding: No funding sources

Conflict of interest: None declared

Ethical approval: Not required

\section{REFERENCES}

1. Joiner A. Tooth colour: a review of the literature. $\mathbf{J}$ Dent. 2004;32(1):3-12.

2. Lee YK, Yu B, Lee SH, Cho MS, Lee CY, Lim HN. Shade compatibility of esthetic restorative materials-A review. Dent Mater. 2010;26(12):1119-26.

3. Lee YK. Translucency of human teeth and dental restorative materials and its clinical relevance. J Biomed Opt. 2015;20(4):045002.

4. Lee YK, Yu B, Zhao GF, Lim JI. Color assimilation of resin composites with adjacent color according to the distance. J Esthet Restor Dent. 2015;27(1):24-32.

5. Holloway JA, Miller RB. The effect of core translucency on the aesthetics of all-ceramic restorations. Pract Periodontics Aesthet Dent. 1997;9(5):567-74.

6. Winter R. Visualizing the natural dentition. J Esthet Dent. 1993;5(3):102-17.

7. Xiong F, Chao Y, Zhu Z. Translucency of newly extracted maxillary central incisors at nine locations. J Prosthet Dent. 2008;100(1):11-7.

8. Xiao B, Walter B, Gkioulekas I, Zickler T, Adelson E, Bala K. Looking against the light: how perception of translucency depends on lighting direction. J Vis. 2014;14(3):17.

9. Johnston WM. Review of translucency determinations and applications to dental materials. J Esthet Restor Dent. 2014;26(4):217-23.

10. Liu MC, Aquilino SA, Lund PS, Vargas MA, Arnold AM, Gratton DG, et al. Human perception of dental porcelain translucency correlated to spectrophotometric measurements. J Prosthodont. 2010;19(3):187-93.

11. Lee YK. Translucency of human teeth and dental restorative materials and its clinical relevance. J Biomed Opt. 2015;20(4):45002.

12. Xiong F, Chao Y, Zhu Z. Translucency of newly extracted maxillary central incisors at nine locations. J Prosthet Dent. 2008;100(1):11-7.

13. Hasegawa A, Ikeda I, Kawaguchi S. Color and translucency of in vivo natural central incisors. J Prosthet Dent. 2000;83(4):418-23.

14. Shetty RM, Bhat AN, Gupta N, Mehta D, Srivatsa G, Singh I. Comparison between Color Spaces of Vita Lumin Shade Guide with Natural Teeth in Bengaluru Population using Spectrocolorimeter: An in vivo Study. J Contemp Dent Pract. 2017;18(8):683-7.

15. Brodbelt RH, Brien WJ, Fan PL, Dib JG, Yu R. Translucency of human dental enamel. J Dent Res. 1981;60(10):1749-53.

16. Schmeling M, Andrada MA, Maia HP, Araújo EM. Translucency of value resin composites used to replace enamel in stratified composite restoration techniques. J Esthet Restor Dent. 2012;24(1):53-8.

17. $\mathrm{Yu} \mathrm{B}, \mathrm{Ahn} \mathrm{JS}$, Lee YK. Measurement of translucency of tooth enamel and dentin. Acta Odontol Scand. 2009;67(1):57-64.

18. Xiao B, Walter B, Gkioulekas I, Zickler T, Adelson E, Bala K. Looking against the light: how perception of translucency depends on lighting direction. J Vis. 2014;14(3):17.

19. Xiao B, Zhao S, Gkioulekas I, Bi W, Bala K. Effect of geometric sharpness on translucent material perception. J Vis. 2020;20(7):10.

20. Vaarkamp J, Bosch JJ, Verdonschot EH. Propagation of light through human dental enamel and dentine. Caries Res. 1995;29(1):8-13.

21. Woo ST, Yu B, Ahn JS, Lee YK. Comparison of translucency between indirect and direct resin composites. J Dent. 2008;36(8):637-42.

22. Yu B, Lee YK. Differences in color, translucency and fluorescence between flowable and universal resin composites. J Dent. 2008;36(10):840-6. 
23. Kim EH, Jung KH, Son SA, Hur B, Kwon YH, Park JK. Effect of resin thickness on the microhardness and optical properties of bulk-fill resin composites. Restor Dent Endod. 2015;40(2):128-35.

24. Siagian JS, Dennis D, Ikhsan T, Abidin T. Effect of Different LED Light-curing Units on Degree of Conversion and Microhardness of Bulk-fill Composite Resin. J Contemp Dent Pract. 2020;21(6):615-20.

25. Pirmoradian M, Hooshmand T, Semnani S, Fadavi F. Degree of conversion and microhardness of bulkfill dental composites polymerized by LED and QTH light curing units. J Oral Biosci. 2020;62(1):107-13.

26. Lassila LV, Nagas E, Vallittu PK, Garoushi S. Translucency of flowable bulk-filling composites of various thicknesses. Chin J Dent Res. 2012;15(1):31-5.

27. Rullman I, Patyna M, Janssen B, Willershausen B. Determination of polymerization shrinkage of different composites using a photoelastic method. Am J Dent. 2017;30(1):16-22.

28. Johnston WM. Review of translucency determinations and applications to dental materials. J Esthet Restor Dent. 2014;26(4):217-23.

29. Lee YK. Criteria for clinical translucency evaluation of direct esthetic restorative materials. Restor Dent Endod. 2016;41(3):159-66.

30. Waki T, Nakamura T, Wakabayashi K, Mutobe Y, Yatani $H$. Adhesive strength between fiberreinforced composites and veneering composites and fracture load of combinations of these materials. Int J Prosthodont. 2004;17(3):364-8.

31. Nakamura T, Waki T, Kinuta S, Tanaka H. Strength and elastic modulus of fiber-reinforced composites used for fabricating FPDs. Int $\mathbf{J}$ Prosthodont. 2003;16(5):549-53.

32. Nakamura $\mathrm{T}$, Tanaka $\mathrm{H}$, Kawamura $\mathrm{Y}$, Wakabayashi K. Translucency of glass-fibrereinforced composite materials. J Oral Rehabil. 2004;31(8):817-21.
33. Mount GJ, Patel C, Makinson OF. Resin modified glass-ionomers: strength, cure depth and translucency. Aust Dent J. 2002;47(4):339-43.

34. Asmussen E. Opacity of glass-ionomer cements. Acta Odontol Scand. 1983;41(3):155-7.

35. Lee YK, Yu B, Zhao GF, Lim JI. Effects of aging and HEMA content on the translucency, fluorescence, and opalescence properties of experimental HEMA-added glass ionomers. Dent Mater J. 2010;29(1):9-14.

36. $\mathrm{Yu}$ B, Lee YK. Comparison of stabilities in translucency, fluorescence and opalescence of direct and indirect composite resins. Eur J Esthet Dent. 2013;8(2):214-25.

37. Kim DH, Park SH. Evaluation of resin composite translucency by two different methods. Oper Dent. 2013;38(3):1-15.

38. Kamishima N, Ikeda T, Sano H. Color and translucency of resin composites for layering techniques. Dent Mater J. 2005;24(3):428-32.

39. Ikeda T, Murata Y, Sano H. Translucency of opaque-shade resin composites. Am J Dent. 2004;17(2):127-30.

40. Kim SJ, Son HH, Cho BH, Lee IB, Um CM. Translucency and masking ability of various opaque-shade composite resins. J Dent. 2009;37(2):102-7.

41. Ciutrila IS, Ghinea R, Colosi HA, López J, Perez MM, Paravina RD, Dudea D. Color compatibility between dental structures and three different types of ceramic systems. BMC Oral Health. 2021;21(1):75.

42. Ikeda T, Sidhu SK, Omata Y, Fujita M, Sano H. Colour and translucency of opaque-shades and body-shades of resin composites. Eur J Oral Sci. 2005;113(2):170-3.

43. Lee YK. Criteria for clinical translucency evaluation of direct esthetic restorative materials. Restor Dent Endod. 2016;41(3):159-66.

Cite this article as: Basudan TA, Alqahtani SJ, Alsalmh OA, Kensara EI, Mughafi MFA, Alamri NA, et al. The translucency of human teeth and its relation to esthetic restorative materials. Int J Community Med Public Health 2021;8:5603-7. 